\title{
Top-down and bottom-up controls on an herbivore on a native and introduced plant in a tropical agricultural landscape
}

\author{
Emma Despland ${ }^{\text {Corresp., } 1}$, Paola Santacruz Endara ${ }^{2}$ \\ 1 Biology Department, Concordia University, Montreal, Quebec, Canada \\ 2 Museo Interactivo de Ciencias, Quito, Ecuador \\ Corresponding Author: Emma Despland \\ Email address: emma.despland@concordia.ca
}

The recent introduction in a tropical agricultural environment of a weedy open-habitat plant (Solanum myriacanthum) and subsequent host range expansion of a common forestedge butterfly (Mechanitis menapis) onto that plant provides an opportunity to examine reconfiguration of tritrophic networks in human-impacted landscapes. The objectives of this study were (1) determine if the caterpillars on the exotic host are more or less limited by plant defenses (bottom-up forces) and if they experience enemy release (decrease of top-down pressure) and (2) define how anthropic open pasture habitat influences the herbivore`s tritrophic niche. Field and laboratory monitoring of larval survival and performance on a native (Solanum acerifolium) host plant and the exotic (S. myriacanthum) host plant were conducted in the Mindo Valley, Ecuador. Plant physical defenses were also measured. Results showed that larval mortality was mostly top-down on S. acerifolium, linked to parasitism, but mostly bottom-up on S. myriacanthum, possibly linked to observed increased plant defenses. Thus, in the absence of co-evolved relationships, herbivores on the exotic host experienced little top-down regulation, but stronger bottom-up pressures from plant defenses. These findings provide a rare empirical example of enemy-free space as a mechanism underlying host-range expansion. $S$. myriacanthum was less colonized in open pastures than in semi-shaded habitats (forest edges, thickets): fewer eggs were found, suggesting limited dispersal of adult butterflies into the harsh open environments, and the survival rate of first instar larvae was lower than on semi-shaded plants, likely linked to the stronger defenses of sun-grown leaves. These findings show how environmental conditions modulate the rewiring of trophic networks in heavily impacted landscapes, and limit a biocontrol by a native herbivore on an invasive plant in open habitats. 


\section{Top-down and bottom-up controls on an herbivore on a}

2 native and introduced plant in a tropical agricultural

3 landscape

Emma Despland ${ }^{1}$, Paola Santacruz-Endara ${ }^{2}$

${ }^{1}$ Biology Department Concordia University, Montreal, Qc, Canada

${ }^{2}$ Museo Interactivo de Ciencias, Quito, Ecuador

Corresponding Author:

Emma Despland ${ }^{1}$

7141 Sherbrooke West, Montreal, Qc, H4B 1R6, Canada

Email address: Emma.Despland@concordia.ca

\section{Abstract}

The recent introduction in a tropical agricultural environment of a weedy open-habitat plant (Solanum myriacanthum) and subsequent host range expansion of a common forest-edge butterfly (Mechanitis menapis) onto that plant provides an opportunity to examine reconfiguration of tritrophic networks in human-impacted landscapes. The objectives of this study were to (1) determine if the survival and performance of caterpillars on the exotic host is more or less limited by plant defenses (bottom-up forces) and if they experience enemy release (decrease of top-down pressure) and (2) define how anthropic open pasture habitat influences the herbivore's tritrophic niche.

Field and common garden monitoring of larval survival and performance on a native (Solanum acerifolium) host plant and the exotic (S. myriacanthum) host plant were conducted in the Mindo Valley, Ecuador. Plant physical defenses were also measured. Results showed that larval mortality was mostly top-down on S. acerifolium, linked to parasitism, but mostly bottomup on S. myriacanthum, possibly linked to observed increased plant defenses. Thus, in the absence of co-evolved relationships, herbivores on the exotic host experienced little top-down control, but stronger bottom-up pressures from plant defenses. These findings provide a rare empirical example of enemy-free space as a mechanism underlying host-range expansion.

S. myriacanthum was less colonized in open pastures than in semi-shaded habitats (forest edges, thickets): fewer eggs were found, suggesting limited dispersal of adult butterflies into the harsh open environments, and the survival rate of first instar larvae was lower than on semishaded plants, likely linked to the stronger defenses of sun-grown leaves. These findings show how environmental conditions modulate the rewiring of trophic networks in heavily impacted landscapes, and limit a biocontrol by a native herbivore on an invasive plant in open habitats. 


\section{Introduction}

38 Changing land use patterns disrupt species` niches, and can lead to new associations (Agosta, 2006), especially in the tropics where high biodiversity imposes strong biotic pressures on organisms (Bonebrake et al., 2010). These novel trophic relationships that arise by ecological fitting are not tightly co-evolved but emerge as a result of the functional traits of species that come in contact with each other (Agosta, 2006). The effects of these new community assemblages on insect herbivores are best understood in a tri-trophic perspective, as top-down effects of predators and parasitoids can determine the host plant range of herbivores and play a significant role in defining their niche (Stireman and Singer, 2018; Vidal et al., 2017). Species invasions and changing land use, in particular land-clearing, redefine niches of herbivorous insects via bottom-up and top-down mechanisms. In increasingly human impacted landscapes, species that are able to expand their ranges to include exotic host plants and to colonize open agricultural habitats are less vulnerable to extinction risk (Despland, 2014; Jahner et al., 2011).

Most tropical herbivorous insects feed on a restricted range of host-plants (Coley and Barone, 1996; Forister et al., 2015), and thus the insect's spatial distribution and habitat use often depend on the distribution of larval host plants. Indeed, the host plant structures the larval ecology of insect herbivores: it imposes direct bottom-up selection pressures and influences topdown pressure from natural enemies (Singer et al., 2004). Exotic plants do not have co-evolved relationships with local herbivores or with the parasitoids and predators on the third trophic level, and novel plant-herbivore associations can show dramatically different outcomes (Sunny et al., 2015). In some cases, the lack of co-evolved relationship implies that insect herbivores have no mechanism to counter plant defenses, resulting in lower performance and survival on the exotic host, leading to herbivory release and explaining how an exotic plant can become invasive (Levine et al., 2004). At the extreme, exotic plants can be evolutionary traps (Keeler and Chew, 2008), if they are accepted as oviposition sites by females, but support little or no larval growth. Conversely, exotic plants can provide enemy-free space to herbivores (Mulatu et al., 2004; Murphy, 2004), promoting host range expansion, even if bottom-up pressure on the novel host is stronger (Lefort et al., 2014). In this case, native herbivores can provide biocontrol of the exotic plant (Sunny et al., 2015). In novel plant-herbivore interactions, the bottom-up pressure from plants can be either greater or less than in co-evolved relationships, but top-down pressure from natural enemies is usually less (Stireman and Singer, 2018). In general, performance and survival are lower for larvae developing on exotic hosts relative to native hosts (Yoon and Read, 2016)

The interactions between a herbivore and its host plants also depend on plant community composition (Agrawal et al., 2006). The novel open pasture habitats created by tropical deforestation and agriculture are dominated by weedy light-demanding plants, often including introduced species. The differences between contiguous semi-shaded secondary forest or thicket habitats and open sunny habitats affect both the insect's mobility and the plant's defenses (Morante-Filho et al., 2016). Harsh environmental conditions in open pastures can limit dispersal of adult butterflies: Scriven et al (2019) found that less than half of the butterfly species captured in a forest were found to disperse into adjacent open areas, and most of the dispersers 


\section{Materials \& Methods}

\section{Study species}

113 Mechanitis menapis specializes on forest edges (Young and Moffett, 1979) and is common in

114 disturbed agricultural landscapes (Santacruz-Endara et al., 2019). Known host plants are in the 
115 Solanum subgenus Leptostemonum (Robinson et al., 2010), the 'spiny Solanums', characterized

116 by sharp epidermal prickles and stellate trichomes (Levin et al., 2006). Caterpillars are

117 gregarious and feed collectively, using silk to avoid plant trichome defenses (Despland, 2019;

118 Despland and Santacruz-Endara, 2016).

119 The study was conducted in the Mindo valley $\left(00^{\circ} 03^{\prime} 44.1^{\prime \prime} \mathrm{S} 78^{\circ} 45^{\prime} 41.7^{\prime \prime} \mathrm{W}\right)$, located in

120 cloud forest at $1250 \mathrm{~m}$ a.s.1. on the Western slope of the Andes in the province of Pichincha,

121 Ecuador. In this region, the main host plant (Santacruz-Endara et al., 2019) is S. acerifolium

122 Dunal sect. Acanthophora, subgenus Leptostemonum (Nee, 2019). One other known host plant

123 (Robinson et al., 2010), S. candidum Lindl sect. Lasiocarpa within subg. Leptostemonum

124 (Whalen et al., 2019), is also found locally. Both are weedy shrubs of secondary vegetation,

125 roadsides, thickets and agricultural landscapes at moderate altitudes across central and south

126 America (Nee, 2019; Whalen et al., 2019). S. myriacanthum Dunal sect. Acanthophora, a weedy

127 shrub of cultivated lands and pastures whose native range spans from Mexico to northern

128 Nicaragua (Nee, 2019), has recently been observed in the Mindo region, and M. menapis appears

129 to have expanded its range to include this novel host (Santacruz-Endara et al., 2019). $S$.

130 myriacanthum uses more open habitats than either $S$. acerifolium or S. candidum, including full-

131 sun pastures where it tends to exclude other vegetation (see Figure 1).

Field survey

133 We conducted a field survey of $S$. acerifolium, S myriacanthum and S. candidum in ecotone 134 habitats ( $\mathrm{N}=300$ plants per species), and of $S$. myriacanthum in open pastures ( $\mathrm{N}=300$ plants)

135 recording the developmental stage of all $M$. menapis individuals seen. The two native host

136 plants, S. acerifolium and S. candidum were never observed in pasture habitats. Cocoons of the

137 parasitoid Hyposoter spp (Ichneumonidae), a common mortality agent of M. menapis in the

138 region (Santacruz-Endara et al., 2019), were also recorded. Field work was conducted on private

139 land, authorized by land-owners (Ignacio de la Torre; Maria Elena Garzon Jaramillo). Specimens

140 were not collected and no field permit was required.

$141 \quad$ Numbers of individuals at each stage was compared between the three plants using a

142 GLM with a Poisson error function, after testing for model assumptions. All statistical analyses

143 were done with the $\mathrm{R}$ 3.5.3 package.

Field survival rates

145 We further monitored the in situ development of M. menapis on S. acerifolium and $S$.

146 myriacanthum in ecotones (numbers from $S$. candidum were too low to warrant continuing the

147 study) and $S$. myriacanthum in open pastures. Plants $(\mathrm{n}=10)$ with $M$. menapis eggs were flagged

148 in three pastures and in adjoining ecotone habitats, and monitored at 3-day intervals for one

149 month (8 observations on each of 90 plants), recording the instar of all observed larvae to

150 reconstruct larval survival. Any apparent causes of mortality were recorded, notably parasitoid

151 cocoons. An instance of parasitism was recorded as the disappearance of a larva and appearance 
152 of a parasitoid cocoon between observations. The rate of parasitism was calculated as the

153 proportion of larvae of a given stadium that were parasitized. At each visit, temperature and solar

154 radiation were recorded in each ecotone and pasture location when the sun was out between 10

155 and $14 \mathrm{~h}$.

156 Analyses compared between the native S. acerifolium and the exotic S. myriacanthum in

157 the ecotone, and between ecotone and pasture S. myriacanthum plants. Survivorship on the two

158 hosts was compared with Kaplan Meier survival analysis: to determine the instar at which

159 differences in survival occur, proportions surviving from one developmental stage to the next

160 were compared with chi-square analyses.

Common garden rearing

Eggs were collected in the field on $S$. acerifolium. Larvae were reared from hatching on potted $S$. acerifolium $(\mathrm{n}=80)$, S. myriacanthum $(\mathrm{n}=80)$ and $S$. candidum $(\mathrm{n}=20)$ plants in a common garden, in an indoor insectary with large mesh screen windows to prevent natural enemy entrance. Ten larvae ( 2 groups of 5 because M. menapis are gregarious (Despland and SantacruzEndara, 2016)) were placed per plant. Conditions were similar to those found in ecotone habitats, including semi-shade and natural photoperiod. As in the field monitoring, the instar of all surviving larvae was recorded every three days. Mass of all surviving individuals was recorded at pupation with a portable balance (Ohaus Scout SPX123).

As in the field monitoring, survival rates between S. acerifolium and S. myriacanthum were compared with Kaplan-Meier survival analysis and with chi-square tests for each larval instar. Pupal masses were compared with t-tests. Survival on $S$. candidum was too low for inclusion in the analysis.

\section{Leaf traits}

175

176

177

178

179

180

181

182

183

184

185

186

187

188
Physical traits were recorded on mid-age leaves (between leaf position 3 to 6 from the apex, the leaves on which M. menapis are generally found) of field-collected ecotone S. acerifolium, $S$. myriacanthum and $S$. candidum ( $\mathrm{N}=20$ plants per species). The density of stellate, simple and glandular hairs on $4 \mathrm{~mm}^{2}$ leaf discs was counted under a stereomicroscope (Nikon Fabre Photo EX microscope, 20x magnification). For each leaf, three discs were punched in the proximal, medial and distal thirds of the leaf, avoiding secondary and tertiary veins, and pooled to create an average value per leaf.

Specific leaf area (SLA) was evaluated on $45 \mathrm{~mm}$ diameter leaf discs, avoiding the midvein, recording fresh and dry mass with the portable balance to calculate water content. Leaf toughness was evaluated as the force to fracture the leaf lamina using a penetrometer (CoboQuinche et al., 2019). Trichome density, water content and SLA were also measured on open habitat S. myriacanthum.

Leaf traits were compared between the three plant species and between ecotone and open-habitat S. myriacanthum using GLMs with the appropriate error function. 
189

190

191

192

193

194

195

196

197

198

199

200

201

202

203

204

205

206

207

208

209

210

211

212

213

214

215

216

217

218

219

220

221

222

223

224

\section{Results}

\section{Field survey}

Of the 300 plants surveyed in ecotone habitats, 182 eggs were observed on S. acerifolium, 174 on $S$. myriacanthum, and only 9 on $S$. candidum (see Figure 2). Data from the native $S$. acerifolium and the exotic $S$. myriacanthum only were included in the analysis, due to the very low numbers on the native $S$. candidum. Numbers observed differed significantly between the two host plants $\left(\mathrm{z}_{598}=0.906, \mathrm{p}<0.0001\right)$, and interaction terms suggested differential survival between host plants at several developmental stages (first instar: $z_{598}=2.97, p=0.002$; second instar $\mathrm{z}_{598}=3.04, \mathrm{p}=0.002$; fourth instar $\mathrm{z}_{598}=2.15, \mathrm{p}=0.03$; fifth instar $\mathrm{z}_{598}=1.94, \mathrm{p}=0.043$ ). Notably Hyposoter parasitoid pupae $(\mathrm{N}=72)$ were only observed on $S$. acerifolium.

On $S$. myriacanthum, more eggs were observed on ecotone plants than on pasture plants $\left(\mathrm{N}=174\right.$ vs $\left.\mathrm{N}=39 ; \chi^{2}=131, \mathrm{p}<0.0001\right)$. Numbers of larvae were not compared due to the extreme difference in initial numbers of eggs. No parasitoid pupae were seen in either habitat type.

\section{Field survival rates}

Kaplan-Meier survivorship curves for native S.acerifolium and exotic S. myriacanthum in ecotones, as well as $S$. myriacanthum in pastures are shown in Fig.3. Survival analysis showed significant differences: $S$. acerifolium vs $S$. myriacanthum in ecotones, z $=7.59, \mathrm{p}<0.0001 ; S$. myriacanthum in ecotone vs pasture, $\mathrm{z}=2.07, \mathrm{p}=0.038$.

Chi-square analysis showed that, in ecotone habitats, survival of first instar larvae was higher on native $S$. acerifolium than on exotic $S$. myriacanthum, but survival late in development was higher on S. myriacanthum (Table 1). Rate of Hyposoter parasitism was high on $S$. acerifolium (15\% for fourth instar larvae, and 37\% for fifth instar larvae) but non-existent on $S$. myriacanthum, potentially explaining the difference in survival rate. Indeed, when parasitized insects were removed from the analysis, the differences in mortality rates in instars $4 \& 5$ lost significance (survival on $S$. acerifolium in instar $4=0.86 ; z=0.87 ; p=0.32$; in instar $5=0.80 ; z$ $=1.11 ; \mathrm{p}=0.15)$.

On $S$. myriacanthum, survival of first instar larvae was higher in the ecotone than in the pasture habitat, but survival rates at subsequent instars did not differ significantly, and overall survival did not differ significantly between habitat types (see Table 1).

Both temperature and luminosity were considerably higher in the pasture than in the ecotone environment $\left(31.6+/-1.6\right.$ s.d ${ }^{\circ} \mathrm{C}$ vs $23.4+/-1.68$ s.d. ${ }^{\circ} \mathrm{C}, 117000 \mathrm{lux}+/-4600$ vs 69 $000+/-11000$ lux respectively).

\section{Common garden performance}

In the common garden, survival was highest on the native $S$. acerifolium, lower on the exotic $S$. myriacanthum (Kaplan Meier survival analysis $\mathrm{z}=2.6 ; \mathrm{p}=0.009$ ), and zero on the native $S$. 
225

226

227

228

229

230

231

232

233

234

235

236

237

238

239

240

241

242

243

244

245

246

247

248

249

250

251

252

253

254

255

256

257

258

259

260

261

candidum $(\mathrm{z}=4.91 ; \mathrm{p}<0.0001)$. Chi-square analysis showed that survival of first instar larvae was higher on $S$. acerifolium than on $S$. myriacanthum, but that survival at later developmental stages did not differ between the two host plants (see Table 2). None of the larvae reared on $S$. candidum survived beyond the first instar.

Pupal mass did not differ significantly between insects reared on $S$. acerifolium and $S$. myriacanthum $\left(167 \mathrm{mg}+/-8\right.$. S.E. $(\mathrm{n}=37)$ vs $160 \mathrm{mg}+/-13$ S.E. $(\mathrm{n}=20)$; t-test $\mathrm{t}_{56}=0.54 ; \mathrm{p}=$ $0.5)$.

\section{Leaf traits}

The trichome profile differed between the three plants tested: $S$. candidum had much higher numbers of stellate trichomes on both leaf surfaces (GLM with quasipoisson link function: $\mathrm{t}_{54}=$ 12.2; $\mathrm{p}<0.0001)$; S. myriacanthum had more simple trichomes (GLM with quasipoisson link function: $\left.\mathrm{t}_{54}=16.5 ; \mathrm{p}<0.0001\right)$ and glandular trichomes (GLM with quasipoisson link function: $\left.\mathrm{t}_{54}=2.10 ; \mathrm{p}=0.004\right)$ on the abaxial surface. No difference was recorded in SLA $\left(\mathrm{F}_{2,57}=2.02, \mathrm{p}\right.$ $=0.14)$ or in water content $\left(\mathrm{F}_{2,57}=1.52, \mathrm{p}=0.228\right)$ between the three species. However, leaves of $S$. myriacanthum were significantly tougher $\left(\mathrm{F}_{2,57}=20.52, \mathrm{p}<0.0001\right)$ than those of $S$. acerifolium or S. candidum (see Fig. 4).

S. myriacanthum growing under full sun showed a greater number of stellate (GLM with quasipoisson link function: $\mathrm{t}_{36}=3.04 ; \mathrm{p}=0.02$ ), simple (GLM with quasipoisson link function: $\mathrm{t}_{36}=3.02 ; \mathrm{p}=0.03$ ), and glandular trichomes (GLM with quasipoisson link function: $\mathrm{t}_{36}=1.90$; $\mathrm{p}=0.04)$ - see Fig 4. SLA was significantly higher in ecotone than in open-area leaves $\left(\mathrm{t}_{38}=46\right.$; $\mathrm{p}<0.0001)$, but water content did not differ $\left(\mathrm{t}_{38}=0.90 ; \mathrm{p}=0.35\right)$.

\section{Discussion}

In response to the first objective, results suggest that bottom-up pressure increased, but top-down control decreased on the exotic, relative to the native, host plant. Indeed, both common garden experimental and field observational results showed different patterns of mortality between $S$. acerifolium and $S$. myriacanthum. In the field, mortality on $S$. acerifolium occurred mostly in the late larval instars, and seemed mostly due to parasitism by Hyposter. By contrast, mortality on $S$. myriacanthum occurred mostly early in development (in both the common garden experiment and in the field), and parasitism was never observed. Removing the effect of parasitoids (by common garden rearing in an insectary or by post-hoc manipulation of field data) led to higher survival on the native than on the exotic plant. Thus, population control of M. menapis on $S$. acerifolium appears mostly top-down, linked to parasitism, whereas limiting factors on $S$. myriacanthum appear more bottom-up, possibly linked to plant defenses.

The high mortality of first instar M. menapis on $S$. myriacanthum is possibly linked to a higher density of simple and glandular trichomes, and to higher toughness compared to the closely related, native $S$. acerifolium. Indeed, glandular trichomes are effective defenses against early-instar M. menapis, limiting the ability of small caterpillars to initiate a feeding edge and 
262 establish themselves on the leaf (Despland, 2019). Phytochemistry likely also plays an important

263

264

265

266

267

268

269

270

271

272

273

274

275

276

277

278

279

280

281

282

283

284

285

286

287

288

289

290

291

292

293

294

295

296

297

298

299

300

301 role (Beccaloni, 1995), but measuring plant chemical defenses was beyond the scope of this study. Overall, our results suggest that the M. menapis host range has expanded to include $S$. myriacanthum; this exotic plant appears to provide enemy-free space, and thus to become a viable host despite strong defenses - for a similar example see Murphy (2004) . Herbivores on chemically defended plants, like the Solanums, can experience a trade-off between host plants with low defenses that support good growth but provide low potential for sequestration of plant compounds as defense against natural enemies, and highly defended plants that support low growth but provide enemy-free space (Mira and Bernays, 2002; Murphy and Loewy, 2015; Zalucki et al., 2012).

The second native host studied, $S$. candidum, did not support survival in the common garden experiment and was very seldom used in the field. $S$. candidum is listed as a M. menapis host plant (Robinson et al., 2010), but clearly is very marginal in our study region. Mechanitis is a species complex in which larval host plant use is an important taxonomic trait; however, most information on host plant use comes from anecdotal records, and does not adequately represent frequency or geographical range of host use, obscuring a clear interpretation of host use patterns (Giraldo and Uribe, 2012). Our results suggest possible genetic differences, in the plant or in the butterfly, between our study region and those where this relationship was observed.

In response to the second objective, results show that open pasture conditions limit the herbivore's expansion onto the exotic host. Fewer M. menapis eggs were found on $S$. myriacanthum plants in pastures and the survival rate of first instar larvae was lower than on ecotone plants. Low oviposition in full sun can arise from butterfly preference for partially shaded habitats. Adult M. menapis were never seen in pastures in the course of the study. Harsh environmental conditions thus appear to play an important role in limiting M. menapis dispersal into pastures (Scriven et al., 2019). Low first instar survival could be linked to the observed higher trichome density and lower SLA (generally a good proxy for greater toughness) of full sun plants. Indeed, within a species, sun leaves are often tougher and bear more trichomes than shade leaves (Kitajima et al., 2016). Leaves of several Solanum species have been shown to be tougher, and to exhibit lower SLA, more trichomes and more allelochemicals when grown in full sun than in partial shade, and the specialist caterpillar Manduca sexta shows lower performance on sun-grown Solanum plants (Jansen and Stamp, 1997). Similarly, herbivores perform better on shade than on sun leaves of Solanum viarum sect. Lasiocarpa, a sister species to $S$. myriacanthum; and, by consequence, plants in shade habitats show more herbivore damage (Diaz et al., 2011).

The novel trophic relationship between $M$. menapis and $S$. myriacanthum is thus modulated by habitat, demonstrating how trophic relationships can reconfigure depauperized communities in heavily disturbed landscapes: in this system, the native host plants are restricted to semi-shade secondary vegetation thickets and ecotone habitats. The arrival of an exotic weed that tolerates the harsh conditions in full sunlight can lead to its rapid proliferation in pastures. Herbivore pressure on the invasive plant is low in pastures, which become herbivore-free space,

PeerJ reviewing PDF | (2019:10:41959:2:1:NEW 11 Feb 2020) 
302 perhaps facilitating the plant's spread. Similarly, the invasion of the closely-related S. viarum in

303 Florida has shown how weedy plants can exhibit different growth patterns and biomass

304 allocation in pastures than in partially-shaded habitats and can spread dramatically in the absence

305 of top-down herbivore control, becoming noxious weeds excluding other vegetation (Diaz et al.,

306 2014).

\section{Conclusions}

308 Our study shows how both plant species invasions and novel habitat creation via land-clearing

309

310

311

312

313

314

315

316

317

318

319

320

321

322

323

324

325

326

327

for agriculture can rewire trophic relationships between the native forest-edge species that dominate tropical agricultural landscapes.

First, our findings support the paradigm that, in the absence of a co-evolved relationship, bottom-up pressure from plant defenses is stronger on exotic hosts, but that herbivores experience less top-down control on these exotic plants, which can ameliorate their value as hosts (Mulatu et al., 2004; Murphy, 2004). The tri-trophic niche can therefore facilitate native herbivore host range expansion onto exotic plants (Stireman and Singer, 2018), and exotic plants can become a valuable resource for insect conservation (Despland, 2014; Jahner et al., 2011).

Second, however, our findings also show that pasture habitat conditions limit colonization of an exotic plant by a native herbivore, and that this herbivore is therefore of little use as a biocontrol agent on a weedy exotic plant that is invading these anthropic habitats. Fullsun pastures in the tropics are harsh microhabitats relative to forest-edges, and generally exhibit low diversity, and are vulnerable to becoming overwhelmed by a few weedy, often exotic, species to the exclusion of other organisms. Thus, although secondary vegetation and thickets can be important biodiversity reservoirs for tropical forest-edge species, pastures constitute a harsh environment that is much less used (Beckerman et al., 2019; Horner-Devine et al., 2003).

\section{Acknowledgements}

Thanks to Tania Iza for help with rearing and field work, and to Rafael Cardenas for help with toughness measurements.

\section{References}

Agosta, S., 2006. On ecological fitting, plant-insect associations, herbivore host shifts, and host plant selection. Oikos 114 .

Agrawal, A.A., Lau, J.A., Hambäck, P.A., 2006. Community heterogeneity and the evolution of interactions between plants and insect herbivores. Q. Rev. Biol. 81, 349-376. https://doi.org/10.1086/511529

Beccaloni, G.W., 1995. Studies on the Ecology and Evolution of Neotropical Ithomiine Butterflies (Nypmhalidae: Ithomiinae) PhD Thesis, University of London, UK.

Beckmann, M., Gerstner, K., Akin-Fajiye, M., Ceaușu, S., Kambach, S., Kinlock, N.L., Phillips, H.R.P., Verhagen, W., Gurevitch, J., Klotz, S., Newbold, T., Verburg, P.H., Winter, M., 
338

339

340

341

342

343

344

345

346

347

348

349

350

351

352

353

354

355

356

357

358

359

360

361

362

363

364

365

366

367

368

369

370

371

372

373

374

375

376

377

378

379

380

381

Seppelt, R., 2019. Conventional land-use intensification reduces species richness and increases production: A global meta-analysis. Glob. Change Biol. 25, 1941-1956. https://doi.org/10.1111/gcb.14606

Bonebrake, T.C., Ponisio, L.C., Boggs, C.L., Ehrlich, P.R., 2010. More than just indicators: A review of tropical butterfly ecology and conservation. https://doi.org/10.1016/j.biocon.2010.04.044

Cobo-Quinche, J., Endara, M.-J., Valencia, R., Muñoz-Upegui, D., Cárdenas, R.E., 2019. Physical, but not chemical, antiherbivore defense expression is related to the clustered spatial distribution of tropical trees in an Amazonian forest. Ecol. Evol. 9, 1750-1763. https://doi.org/10.1002/ece3.4859

Coley, P.D., Barone, J.A., 1996. Herbivory and plant defenses in tropical forests. Annu. Rev. Ecol. Evol. Syst. 27, 305-335.

Despland, E., 2019. Caterpillars cooperate to overcome plant glandular trichome defenses. Front. Ecol. Evol. 7. https://doi.org/10.3389/fevo.2019.00232

Despland, E., 2014. Butterflies of the high-altitude Atacama desert: habitat use and conservation. Front. Genet. 5.

Despland, E., Santacruz-Endara, P., 2016. Silk drives aggregation and following in the neotropical Ithomiine caterpillar Mechanitis menapis. Physiol. Entomol. 41, 274-280.

Diaz, R., Aguire, C., Wheeler, G., Lapointe, S., Rosskopf, E., Overholt, W.A., 2011. Differential performance of tropical soda apple and its biological control agent Gratiana boliviana (Coleoptera: Chrysomelidae) in open and shaded habitats. Environ. Entomol. 40, 14371447.

Diaz, R., Manrique, V., Hibbard, K., Fox, A., Roda, A., Gandolfo, D., Mckay, F., Medal, J., Hight, S., Overholt, W.A., 2014. Successful biological control of tropical soda apple (Solanales: Solanaceae) in Florida: a review of key program components. BioOne 97, 179-190.

Forister, M.L., Novotny, V., Panorska, A.K., Baje, L., Basset, Y., Butterill, P.T., Cizek, L., Coley, P.D., Dem, F., Diniz, I.R., Drozd, P., Fox, M., Glassmire, A.E., Hazen, R., Hrcek, J., Jahner, J.P., Kaman, O., Kozubowski, T.J., Kursar, T.A., Lewis, O.T., Lill, J., Marquis, R.J., Miller, S.E., Morais, H.C., Murakami, M., Nickel, H., Pardikes, N.A., Ricklefs, R.E., Singer, M.S., Smilanich, A.M., Stireman, J.O., Villamarín-Cortez, S., Vodka, S., Volf, M., Wagner, D.L., Walla, T., Weiblen, G.D., Dyer, L.A., 2015. The global distribution of diet breadth in insect herbivores. Proc. Natl. Acad. Sci. 112, 442447. https://doi.org/10.1073/pnas.1423042112

Giraldo, C.E., Uribe, S.I., 2012. Taxonomy of Mechanitis (F.) (Lepidoptera: Nymphalidae) from the West Colombian Andes: an integrative approach. Neotrop. Entomol. 41, 472-484.

Horner-Devine, M., Daily, G.C., Ehrlich, P.R., Boggs, C.L., 2003. Countryside biogeography of tropical butterflies. Conserv. Biol. 17, 168-177. https://doi.org/10.1046/j.15231739.2003.01310.x

Jahner, J.P., Bonilla, M.M., Badik, K.J., Shapiro, A.M., Forister, M.L., 2011. Use of exotic hosts by Lepidoptera: widespread species colonize more novel hosts. Evolution 65, 19-24.

Jansen, M.P.T., Stamp, N.E., 1997. Effects of light availability on host plant chemistry and the consequences for behavior and growth of an insect herbivore. Entomol. Exp. Appl. 82, 319-322. 
382 Keeler, M.S., Chew, F.S., 2008. Escaping an evolutionary trap: preference and performance of a

383

384

385

386

387

388

389

390

391

392

393

394

395

396

397

398

399

400

401

402

403

404

405

406

407

408

409

410

411

412

413

414

415

416

417

418

419

420

421

422

423

424

425

426 native insect on an exotic invasive host. Oecologia 156, 559-568. https://doi.org/10.1007/s00442-008-1005-2

Kitajima, K., Wright, S.J., Westbrook, J.W., 2016. Leaf cellulose density as the key determinant of inter- and intra-specific variation in leaf fracture toughness in a species-rich tropical forest. Interface Focus 6, 20150100. https://doi.org/10.1098/rsfs.2015.0100

Lefort, M.-C., Boyer, S., Romans, S.D., Glare, T., Armstrong, K., Worner, S., 2014. Invasion success of a scarab beetle within its native range: host range expansion versus host-shift. PeerJ 2, e262. https://doi.org/10.7717/peerj.262

Levin, R.A., Myers, N.R., Bohs, L., 2006. Phylogenetic relationships among the "spiny solanums" (Solanum subgenus Leptostemonum, Solanaceae). Am. J. Bot. 93, 157-169.

Levine, J.M., Adler, P.B., Yelenik, S.G., 2004. A meta-analysis of biotic resistance to exotic plant invasions. Ecol. Lett. 7, 975-989.

Maiorana, V.C., 1981. Herbivory in sun and shade. Biol. J. Linn. Soc. 15, 151-156.

Mira, A., Bernays, E.A., 2002. Trade-offs in host use by Manduca sexta: plant characters vs natural enemies. Oikos 97, 387-397. https://doi.org/10.1034/j.1600-0706.2002.970309.x

Morante-Filho, J.C., Arroyo-Rodriguez, V., Lohbeck, M., Tscharntke, T., Faria, D., 2016. Tropical forest loss and its multitrophic effects on insect herbivory. Ecology 97, 33153325.

Mulatu, B., Applebaum, S.W., Coll, M., 2004. A recently acquired host plant provides an oligophagous insect herbivore with enemy-free space. Oikos 107, 231-238. https://doi.org/10.1111/j.0030-1299.2004.13157.x

Murphy, S.M., 2004. Enemy-free space maintains swallowtail butterfly host shift. Proc. Natl. Acad. Sci. 101, 18048-18052.

Murphy, S.M., Loewy, K.J., 2015. Trade-offs in host choice of an herbivorous insect based on parasitism and larval performance. Oecologia 179, 741-751.

Nee, M., 2019a. Solanum acerifolium, in: Solanaceae Source. http://solanaceaesource.org/taxonomy/term/105367/descriptions, consulted 25 June 2019.

Nee, M., 2019b. Solanum myriacanthum, in: Solanaceae Source. http://solanaceaesource.org/taxonomy/term/108387/descriptions, Consulted 25 June 2019.

Robinson, G.S., Ackery, P.R., Kitching, I.J., Beccaloni, G.W., Hernandez, L.M., 2010. HOSTS A Database of the World's Lepidopteran Hostplants.

Santacruz-Endara, P., Despland, E., Giraldo, C.E., 2019. Ciclo de vida y enemigos naturales de Mechanitis menapis (Lepidoptera: Ithomiini). Rev. Biol. Trop. 67, 1488-1504.

Scriven, S.A., Beale, C.M., Benedick, S., Hill, J.K., 2019. Barriers to dispersal of rain forest butterflies in tropical agricultural landscapes. Biotropica 49, 206-216. https://doi.org/10.1111/btp.12397

Singer, M.S., Rodrigues, D., Stireman, J.O., Carrière, Y., 2004. Roles of food quality and enemy-free space in host use by a generalist insect herbivore. Ecology 85, 2747-2753.

Stireman, J.O., Singer, M.S., 2018. Tritrophic niches of insect herbivores in an era of rapid environmental change. Current Opinion in Insect Science 29:117-125 https://doi.org/10.1016/j.cois.2018.07.008

Sunny, A., Diwakar, S., Sharma, G.P., 2015. Native insects and invasive plants encounters. Arthropod-Plant Interactions 9, 323-331. https://doi.org/10.1007/s11829-015-9384-X 
427 428 429 430 431 432 433 434 435 436 437 438 439 440 441
Vidal, M.C., Murphy, S.M., Christoph, S., 2017. Bottom-up vs. top-down effects on terrestrial insect herbivores: a meta-analysis. Ecol. Lett. 21, 138-150. https://doi.org/10.1111/ele.12874

Whalen, M.D., Costlich, D.E., Heiser, C.B., 2019 Solanum candidum, in: Solanaceae Source. http://solanaceaesource.org/taxonomy/term/106086/descriptions, consulted on 25 June 2019.

Yoon, S., Read, Q., 2016. Consequences of exotic host use: impacts on Lepidoptera and a test of the ecological trap hypothesis. Oecologia 181, 985-996. https://doi.org/10.1007/s00442016-3560-2

Young, A.M., Moffett, M.W., 1979. Studies on the population biology of the tropical butterfly Mechanitis isthmia in Costa Rica. Am. Midl. Nat. 101, 309-319.

Zalucki, M., Malcolm, S.B., Hanlon, C.C., Paine, T.D., 2012. First-instar monarch larval growth and survival on milkweeds in southern California: effects of latex, leaf hairs and cardenolides. Chemoecology 22, 75-88. 


\section{Table $\mathbf{1}$ (on next page)}

Field survival rates at each larval instar on native $S$ acerifolium vs exotic $S$. myriacanthum in ecotones, as well as exotic $S$. myriacanthum in ecotone vs pasture habitats.

Chi-square with one degree of freedom and P-values are given - significant values are shown in bold. 
1

2 Table 1: Field survival rates at each larval instar on native $S$ acerifolium vs exotic $S$. myriacanthum in

3 ecotones, as well as exotic S. myriacanthum in ecotone vs pasture habitats. Chi-square with one degree

4 of freedom and P-values are given - significant values are shown in bold.

5

\begin{tabular}{lcccccc}
\hline Field survey & Instar 1-2 & Instar 2-3 & Instar 3-4 & Instar 4-5 & I 5 - pupa & overall \\
\hline native & $\mathbf{0 . 6 6}$ & 0.88 & 0.92 & $\mathbf{0 . 6 1}$ & $\mathbf{0 . 3 2}$ & 0.11 \\
exotic & $\mathbf{0 . 2 1}$ & 0.81 & 0.87 & $\mathbf{0 . 8 3}$ & $\mathbf{0 . 7 2}$ & 0.09 \\
Rate $\chi 2$ & $\mathbf{1 0 4}$ & 1.29 & 0.61 & $\mathbf{4 . 0 1}$ & $\mathbf{8 . 4 8}$ & 0.49 \\
p-value & $(<\mathbf{0 . 0 0 0 1 )}$ & $(0.25)$ & $(0.42)$ & $\mathbf{( 0 . 0 4 )}$ & $\mathbf{( 0 . 0 0 4 )}$ & $(0.67)$ \\
\hline ecotone & $\mathbf{0 . 2 1}$ & 0.81 & 0.87 & 0.83 & 0.72 & 0.09 \\
pasture & $\mathbf{0 . 1 6}$ & 0.81 & 0.93 & 0.81 & 0.65 & 0.06 \\
Rate $\chi 2$ & $\mathbf{4 . 2 2}$ & 2.44 & 2.62 & 1.31 & 1.50 & 3.28 \\
p-value & $\mathbf{( 0 . 0 4 )}$ & $(0.12)$ & $(0.11)$ & $(0.26)$ & $(0.22)$ & $(0.07)$ \\
\hline
\end{tabular}

6

7 


\section{Table 2 (on next page)}

Laboratory survival rates at each larval instar on native $S$. acerifolium and exotic $S$. myriacanthum.

Chi-square with one degree of freedom and P-values are given - significant values are shown in bold. 
1 Table 2: Laboratory survival rates at each larval instar on native $S$. acerifolium and exotic $S$.

2 myriacanthum. Chi-square with one degree of freedom and P-values are given - significant values are 3 shown in bold.

4

\begin{tabular}{lcccccc}
\hline Lab rearing & Instar 1-2 & Instar 2-3 & Instar 3-4 & Instar 4-5 & I 5 to pupa & overall \\
\hline S. acerifolium & 0.61 & 0.96 & 0.96 & 0.95 & 0.86 & 0.45 \\
S. myriacanthum & 0.36 & 0.93 & 0.89 & 0.96 & 0.78 & 0.22 \\
Rate X2 & $\mathbf{9 . 0 3}$ & $<0.001$ & 0.42 & $<0.001$ & 0.02 & $\mathbf{7 . 1 2}$ \\
p-value & $\mathbf{( 0 . 0 0 3 )}$ & $(0.98)$ & $(0.51)$ & $(0.99)$ & $(0.89)$ & $\mathbf{( 0 . 0 0 8 )}$ \\
\hline
\end{tabular}

5 
Figure 1

Host plants used by M. menapis in the study region.

(A) S. acerifolium, native. (B) S. myriacanthum, exotic. (C) S. candidum, native. A fourth instar larva is visible on the underside of the $S$. candidum leaf 

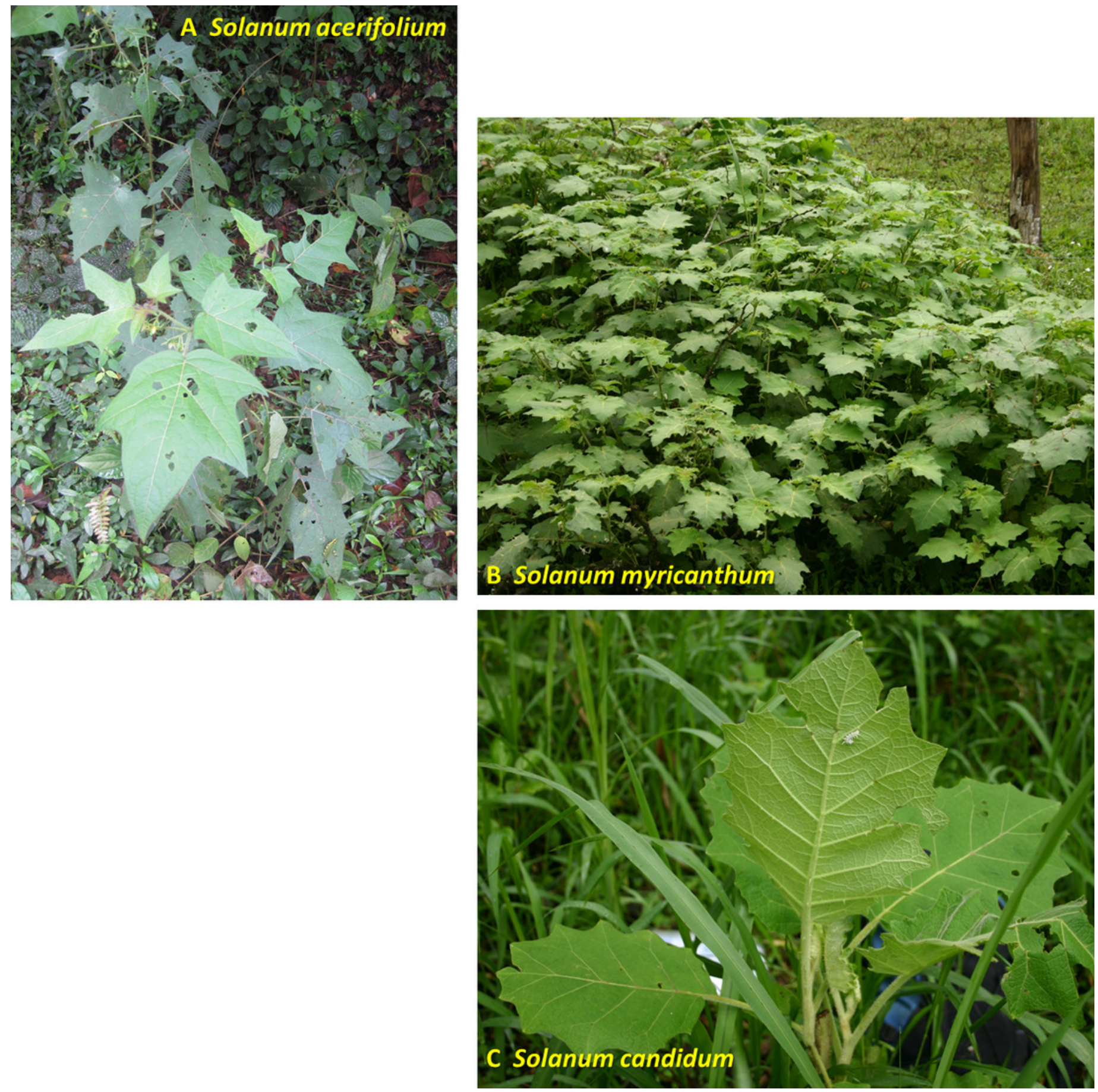
Figure 2

Number of M. menapis eggs, pupae and larvae of each stadium (L1-L5) observed on each of the host plant types in the field survey: S. acerifolium, S. candidum and $S$. myriacanthum in ecotone habitats, and $S$. myriacanthum in pas

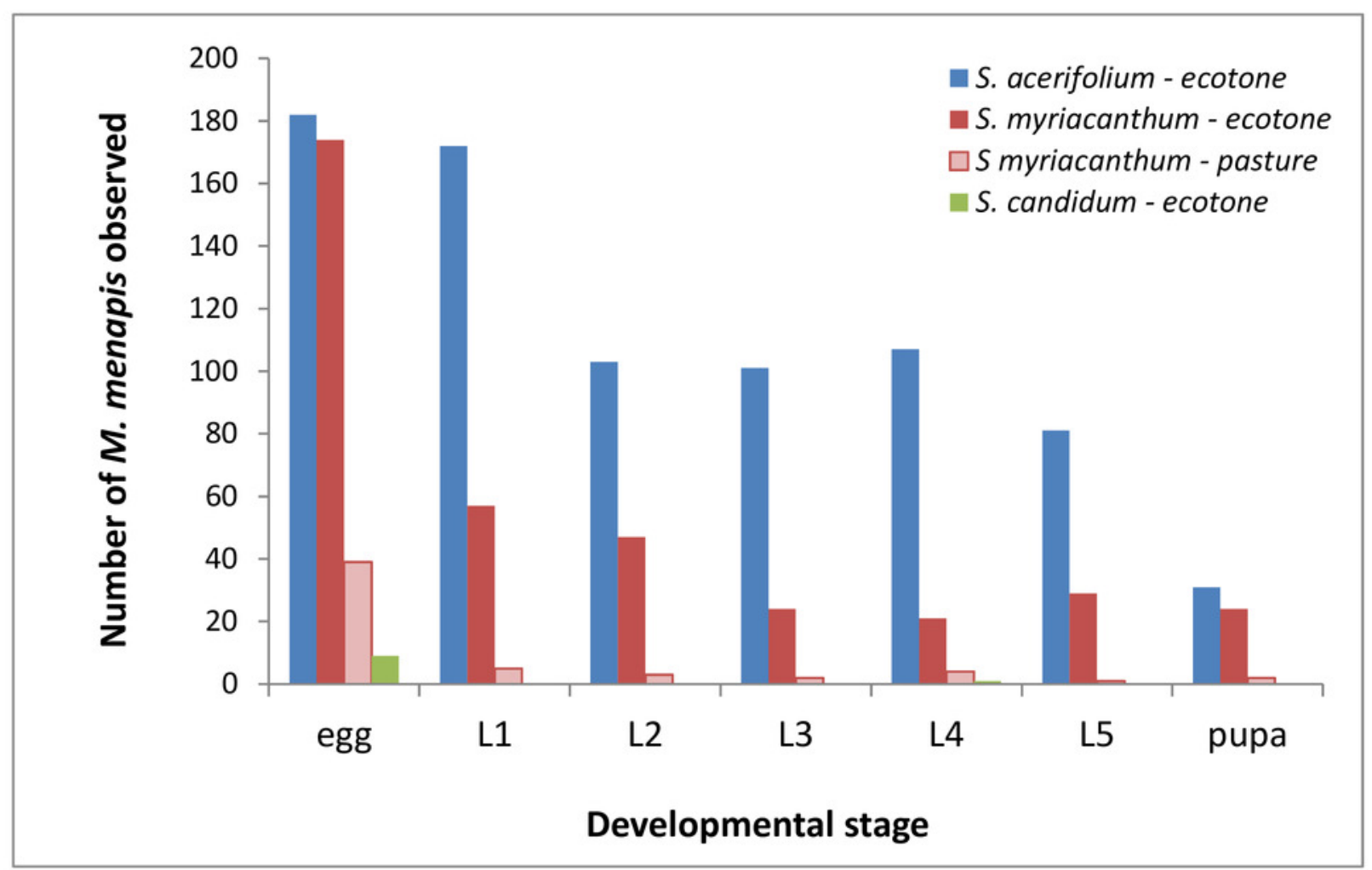


Figure 3

Survivorship curves for M. menapis larvae on the various host plants tested.

A. native $S$. acerifolium and exotic $S$. myriacanthum in ecotone habitats and $S$. myriacanthum in pasture habitats; B. S. acerifolium S. myriacanthum and S. candidum in the laboratory 

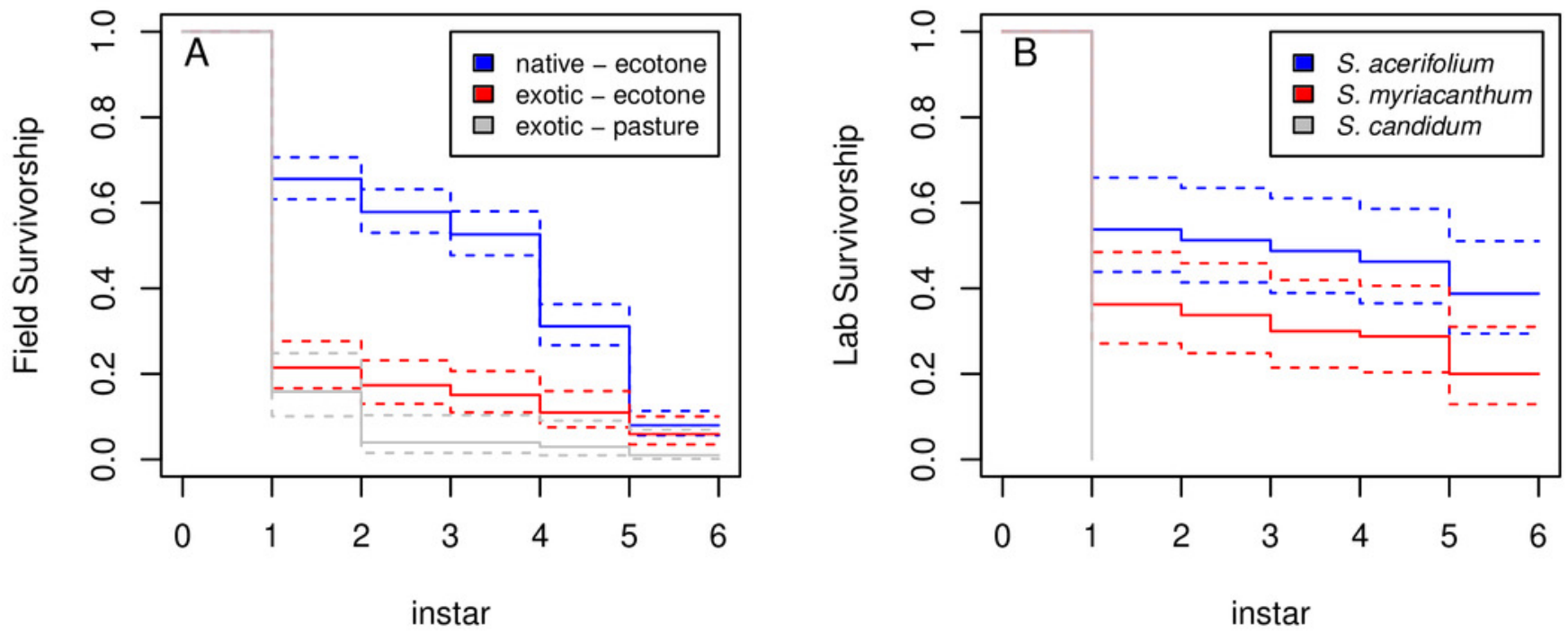
Figure 4

Number of trichomes and leaf traits on all three host plants in ecotones, as well as on $S$. myriacanthum in open habitats

. Traits include: (A) stellate. (B) simple. (C) glandular hairs. (D) water content. (E) SLA. (F) toughness. Toughness data for open habitat S. myriacanthum is unfortunately not available. 

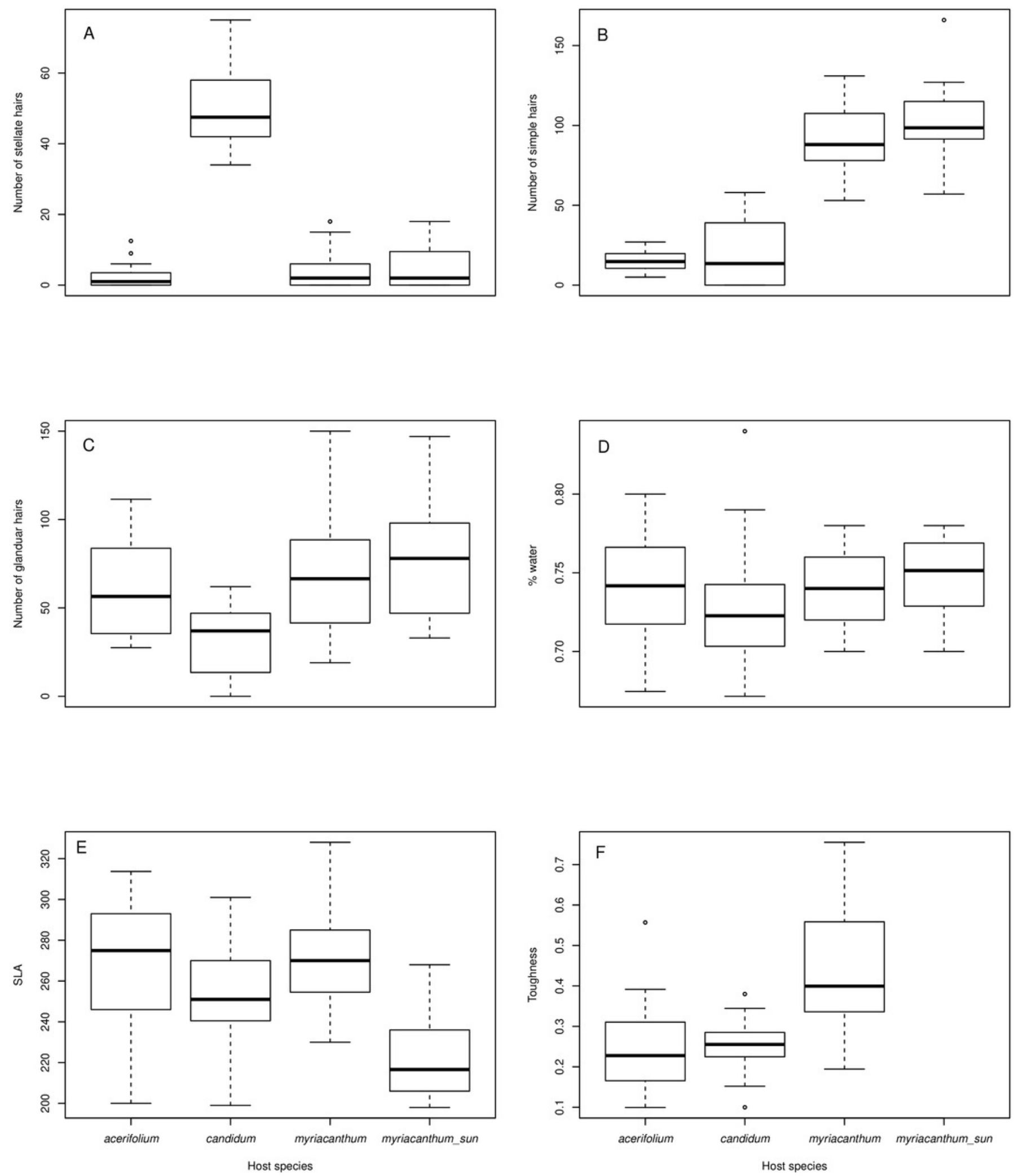